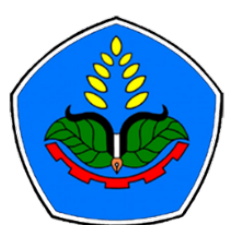

AGROPROSS

National Conference

Proceedings of Agriculture

\title{
Proceedings:
}

Peningkatan Produktivitas Pertanian Era Society 5.0 Pasca Pandemi

Tempat : Politeknik Negeri Jember

Tanggal : 22 Juli 2021

Publisher :

Agropross, National Conference Proceedings of Agriculture

ISBN : 978-623-94036-6-9

DOI : 10.25047 /agropross.2021.215

\section{Pemetaan Kesehatan Tanaman Jeruk Dengan Metode Supervised Classification Berdasarkan Hasil Citra Drone}

\author{
Author(s): Buyung Al Fanshuri( ${ }^{(1)^{*}}$, Yunimar $^{(1)}$ \\ (1) Balai Penelitian Jeruk dan Buah Subtropika \\ * Corresponding author: buyung.fanshuri@gmail.com
}

\section{ABSTRACT}

The area of citrus plantations is reported to have decreased in some areas. This is caused by several things, including disease attacks and lack of care. The Central Statistics Agency (BPS) only provides production area data, so that information on the area of diseased plants does not yet exist. Monitoring the condition of plants can use remote sensing. This study aims to develop remote sensing methods with drones to detect the health of citrus plants. The experimental location was carried out in Banyuwangi using a Phantom 4 drone with an RGB camera. The photos were analyzed using agisoft photoscan software in several stages, namely: align photos, build dense Keywords:

orange;

remote sensing,

drone;

unsupervised classification. clouds, build digital elevation models, build orthomosaic and export geotiffs. Hundreds of photos will become a single image with the process. The results of the image process are then analyzed in QGIS software using the Supervised Classification method. Experiments were carried out on young and mature plants. With this method, the health classification of mature citrus plants can be divided into three, namely: healthy, sick and dead. These results may be less biased than in young plants.

\section{Kata Kunci:}

Jeruk; penginderaan jauh;

drone; unsupervised classification.

ABSTRAK

Luas tanaman jeruk dilaporkan mengalami penurunan di beberapa daerah. Hal tersebut disebabkan oleh beberapa hal, diantaranya serangan penyakit dan kurangnya perawatan. Badan Pusat Statistik (BPS) hanya menyediakan data luasan produksi saja sehingga informasi tentang luasan tanaman yang sakit belum ada. Pemantauan kondisi tanaman dapat menggunakan penginderaan jauh. Penelitian ini bertujuan untuk mengembangkan metode penginderaan jauh dengan drone untuk mendeteksi kesehatan tanaman jeruk. Lokasi percobaan dilakukan di Banyuwangi dengan menggunakan drone phantom 4 dengan kamera RGB. Hasil foto dianalisa menggunakan software agisoft photoscan dalam beberapa tahap, yaitu: align photos, build dense cloud, build digital elevation model, build orthomosaic dan export geotiff. Ratusan foto akan menjadi satu kesatuan gambar dengan proses tersebut. Hasil proses gambar tersebut kemudian di analisa di software QGIS dengan metode Supervised Classification. Percobaan dilakukan pada tanaman muda dan dewasa. Dengan metode tersebut klasifikasi kesehatan tanaman jeruk dewasa dapat dibagi menjadi tiga, yaitu : sehat, sakit dan mati. Hasil ini kemungkinan bias lebih sedikit dibandingkan pada tanaman muda.
\end{abstract}




\section{PENDAHULUAN}

Tanaman jeruk dapat beradaptasi dengan baik di berbagai negara di dunia. Jeruk dapat tumbuh dengan baik pada daerah tropis dan subtropis, berkisar pada zona $40^{\circ} \mathrm{LU}$ and $40^{\circ} \mathrm{LS}$ dari khatulistiwa (CDCGC, 2004; Zabihi et al., 2016; Zabihi et al., 2017). Oleh karena itu, tanaman jeruk mampu beradaptasi di Indonesia. Pada tahun 2012, dilaporkan bahwa produksi jeruk nasional tercatat 1.611 .768 ton (Statistik Produksi Hortikultura Tahun 2014, 2015).

Penurunan luas pertanaman dilaporkan di beberapa daerah. Menurut Supriyanto (2010), pertanaman jeruk di Kabupaten Sambas terinfeksi penyakit CVPD dengan luas serangan hampir $30 \%$. Kabupaten Sambas di Kalimantan Barat merupakan salah satu sentra utama jeruk di Indonesia. Dengan luas tanam sekitar 12.000 ha, Sambas mampu memproduksi jeruk Siam Pontianak sekitar 120.000 ton per tahun.

Laporan luas pertanaman dan luas produksi yang dilaporkan BPS setiap tahunnya berasal dari data dinas pertanian. Metode yang umumnya digunakan adalah survey. Penyebab penurunan luas pertanaman dan produksi belum terkelompokkan dengan baik. Misalnya, kematian karena stress abiotik, kurangnya perawatan dan ataukah karena penyakit. Laporan monitoring yang sifatnya rutin tentang kondisi tanaman juga masih kurang.

Teknik pemantauan suatu wilayah berbasis spasial umumnya menggunakan penginderaan jauh. Metode penginderaan jauh berbasis satelit telah banyak digunakan untuk memantau suatu kejadian bencana, misalnya wilayah banjir dan tanah longsor. Pada saat ini, metode ini juga digunakan di bidang pertanian untuk memantau pertanaman padi. Teknik inilah yang dikembangkan dalam aplikasi KATAM (Kalender tanam) yang dihasilkan oleh Badan litbang pertanian.

Penginderaan jauh umumnya menggunakan citra satelit beresolusi sedang $(30$ x $30 \mathrm{~m})$. Hal ini dikarenakan ketersediaan citranya yang bersifat gratis. Jika menggunakan resolusi tinggi akan berbayar. Resolusi sedang ini mempunyai kelemahan dalam pemantauan objek yang tidak luas. Sehingga metode ini tidak cocok digunakan untuk memantau kebun jeruk. Hal ini dikarenakan umumnya kebun jeruk di Indonesia tidak bersifat hamparan yang luas, hanya spot-spot kecil yang tidak luas.

Berdasarkan hal tersebut diatas, maka metode penginderaan jauh yang mungkin dilakukan untuk memantau kebun jeruk adalah citra foto resolusi tinggi. Salah satu pengambilan foto resolosi tinggi yang sekarang berkembang adalah pemetaan dengan UAV (Unmanned Aerial Vehicle) atau biasa disebut drone. Makalah ini menyajikan cara memantau kesehatan tanaman jeruk dengan menggunakan citra foto drone.

\section{BAHAN DAN METODE}

Penelitian ini dilaksanakan pada bulan Agustus tahun 2018 di kebun jeruk petani di desa Plampangrejo Kecamatan Cluring Kabupaten Banyuwangi. Bahan yang digunakan dalam penelitian ini adalah tanaman jeruk berumur 1 tahun (percobaan tanaman muda) dan 7 tahun (percobaan tanaman dewasa) dengan varietas siam pontianak. Lahan jeruk mempunyai topografi datar (kemeringan lereng $0 \%$ ).

Alat yang digunakan adalah drone Phantom 4 dengan kamera RGB (Red Green Blue). Drone diterbangkan pada ketinggian $100 \mathrm{~m}$ dpl. Aplikasi yang digunakan untuk rute penerbangan dan pengambilan foto adalah drone deploy. Hasil foto kemudian diproses untuk mendapatkan gambar secara utuh menggunakan software Agisoft Photoscan Profesional. Klasifikasi citra menggunakan metode supervised classicication yang dianalisa dengan software QGIS.

\section{HASIL DAN PEMBAHASAN}

Penggunaan drone untuk pemetaan di bidang pertanian sedang menjadi tren sekarang ini. Menurut Rokhmana (2015), 
keunggulannya adalah resolusi yang tinggi $( \pm 5 \mathrm{~cm})$ sehingga mudah untuk mengetahui batas lahan di tanaman padi, namun kelemahannya adalah kanopi pohon tinggi menutupi batas sehingga terkadang sulit untuk mendelineasi batasnya. Penerapan teknologi ini sudah dilakukan pada; dukungan perkiraan biomassa tanaman jati, pengukuran luas tanaman padi, penghitungan tanaman kelapa sawit dan pengukuran vigor tanaman tebu.

$$
\text { Penelitian ini mencoba }
$$
mengaplikasikan penggunaan drone untuk tanaman jeruk. Citra resolusi tinggi sangat dibutuhkan pada tanaman jeruk dikarenakan luas pertanaman jeruk yang sempit dan tidak bersifat hamparan. Dengan citra resolusi tinggi akan terlihat individu tanaman jeruk sehingga memudahkan untuk menginterpretasikannya. Hasil foto dengan drone di kebun jeruk tersaji di gambar 2 .

Dalam skala kebun yang memerlukan foto dalam jumlah banyak maka dilakukan penyatuan foto untuk menghasilkan satukesatuan dan kemudian mengintrepretasikannya dengan dengan metode yang tersaji pada gambar 1. Hasil percobaan pertama pada tanaman muda yang kanopinya masih renggang tersaji pada gambar 3. Tanaman muda jika dilihat dari atas akan nampak bahwa kanopi antar tanaman belum saling menutup sehingga objek yang terdeteksi akan semakin banyak.

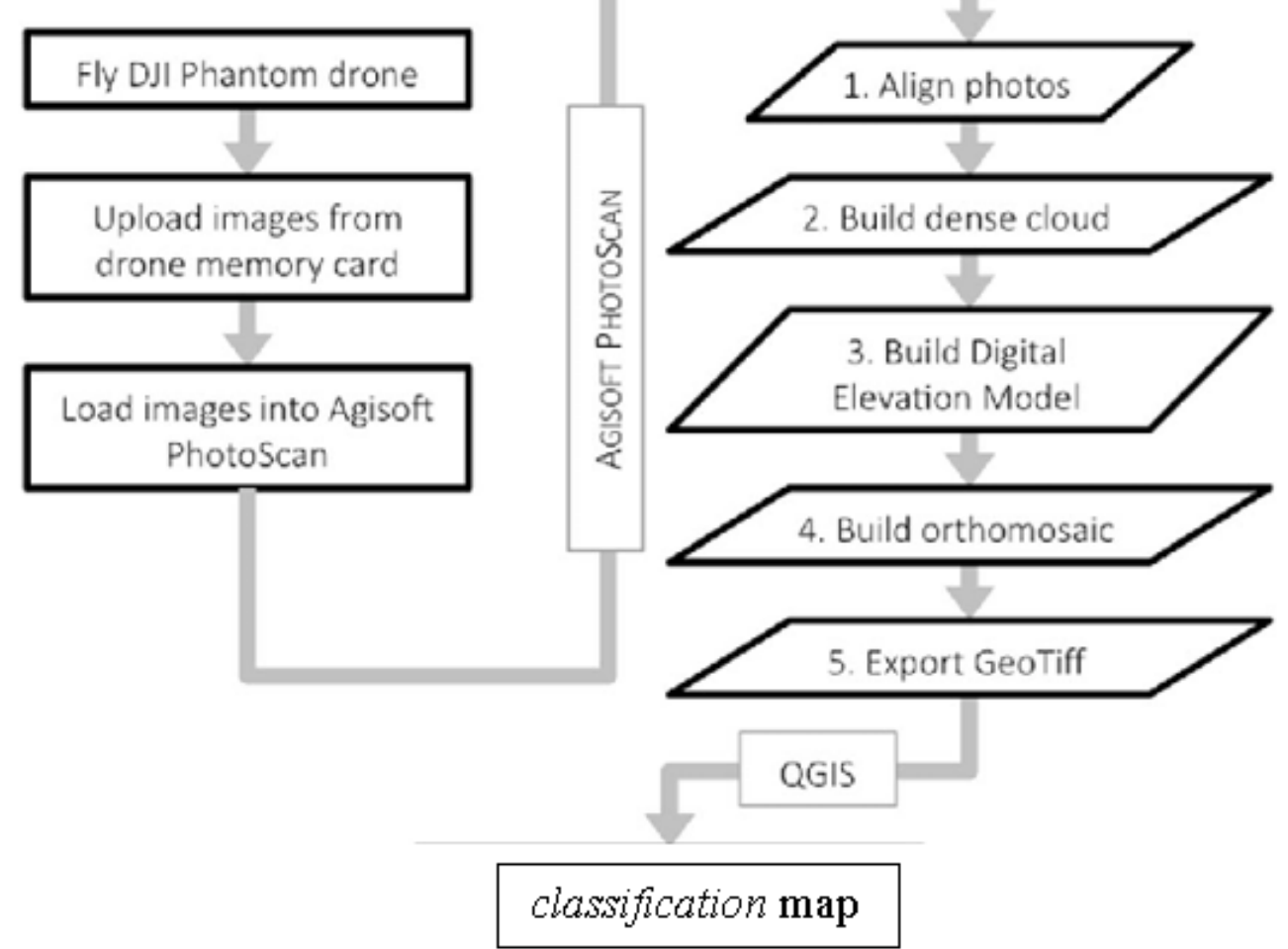

Gambar 1. Alur penyusunan peta kesehatan tanaman jeruk 


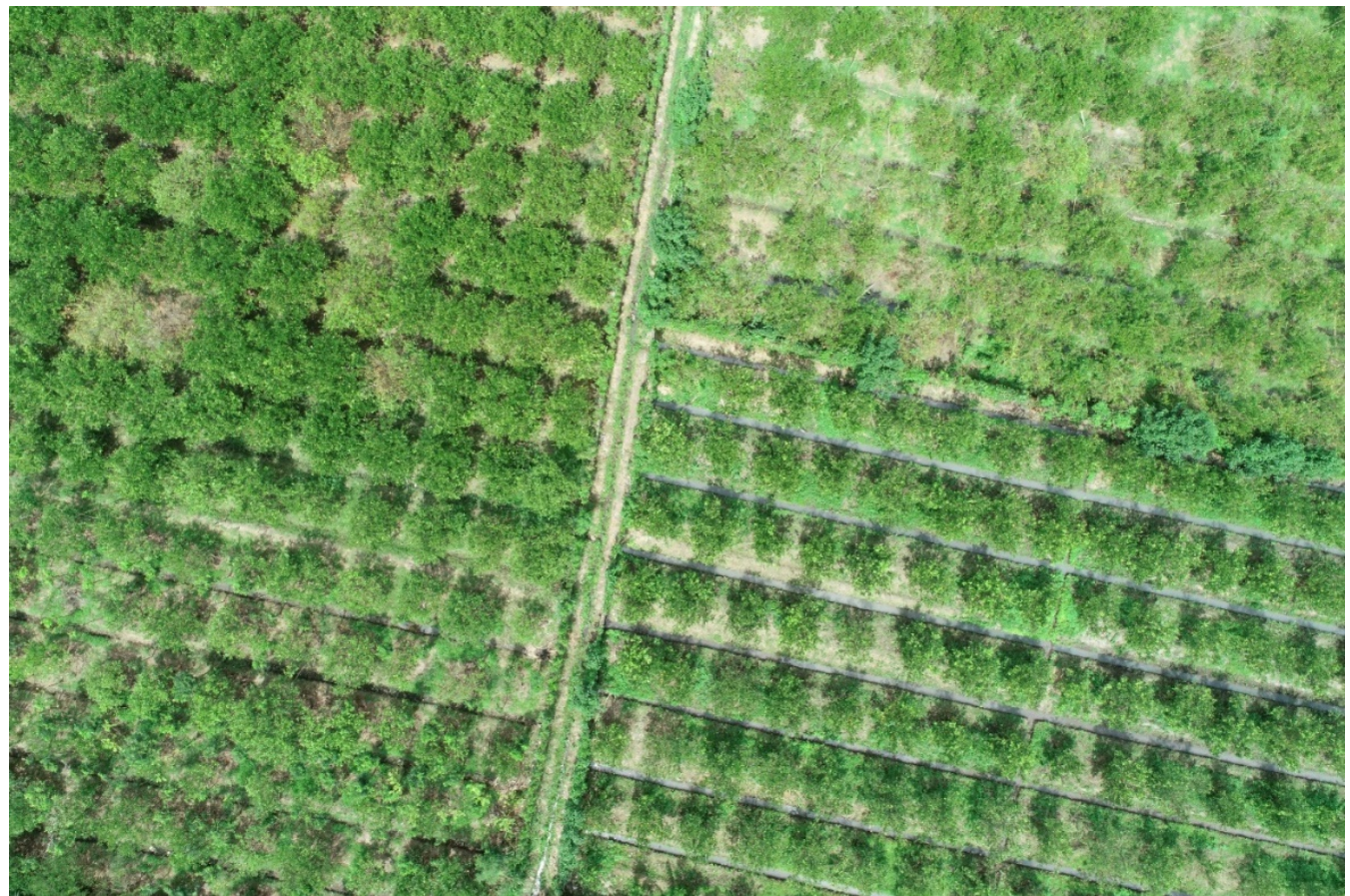

Gambar 2. Hasil foto drone yang sangat jelas tanaman jeruk per individu

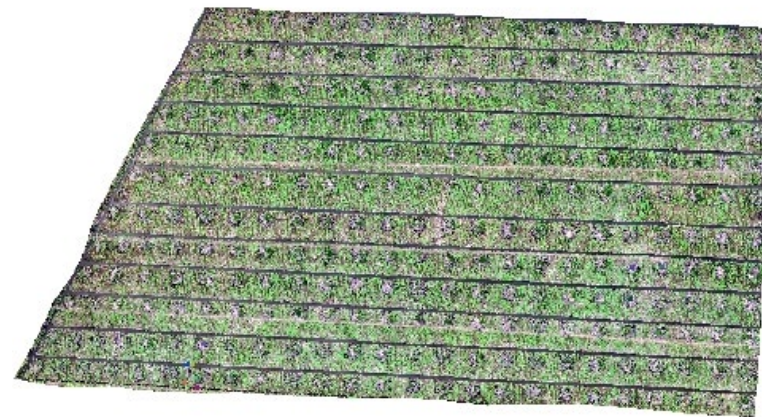

(a)

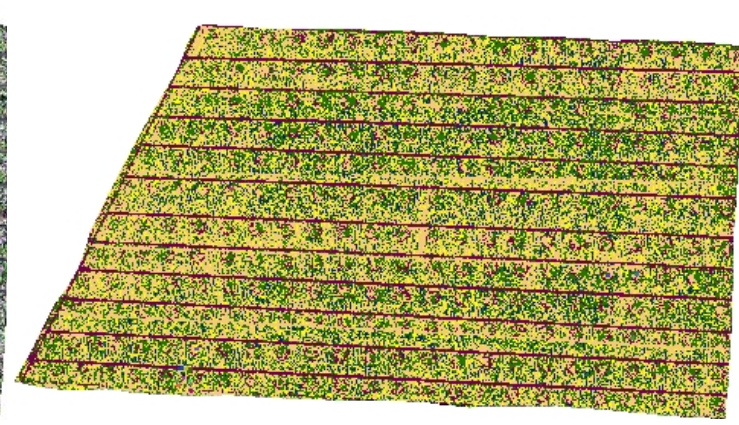

(b)

Gambar 3. Citra foto (a) drone dan peta klasifikasi (b) pada tanaman jeruk muda

\section{PERCENT AREA}

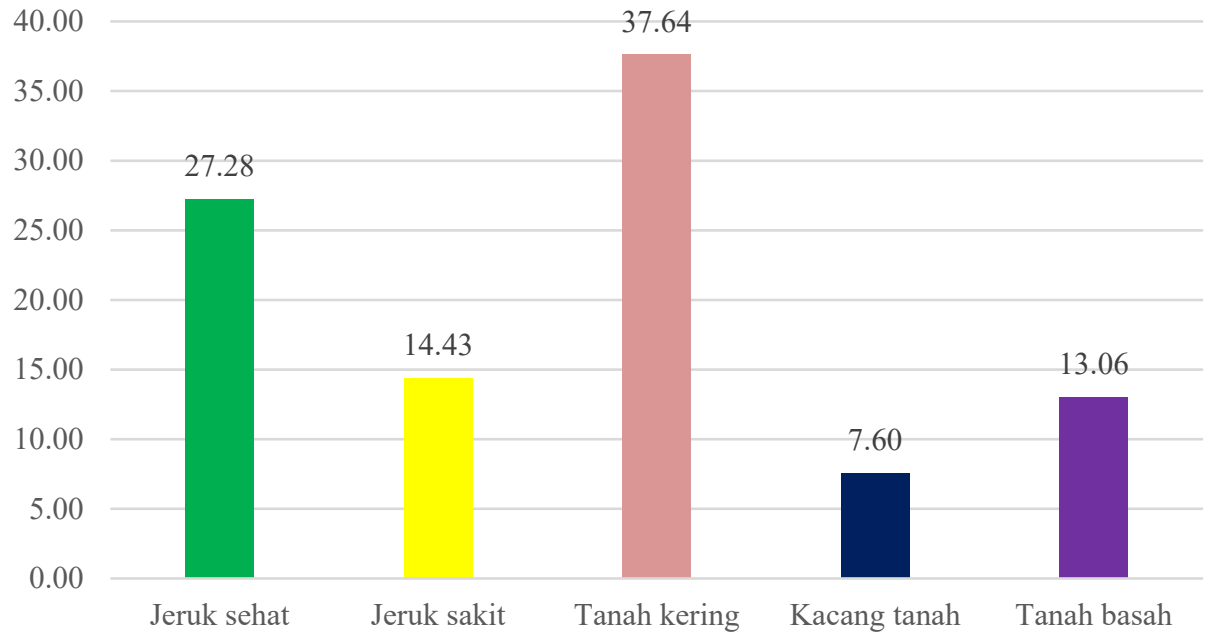

Gambar 4. Prosentase luas area klasifikasi citra drone pada tanaman muda 
Klasifikasi citra pada tanaman muda dengan analisa unsupervised classification menghasilkan 5 (lima) kelas (gambar 4). Klasifikasi lima kelas didasarkan pada intrepretasi objek foto. Hasil ini masih memungkinkan mempunyai bias yang tinggi dikarenakan adanya tanaman sela kacang tanah yang reflektan daunnya akan mirip dengan jeruk. Hal ini merupakan kelemahan dari penggunaan kamera RGB (Red Green Blue).

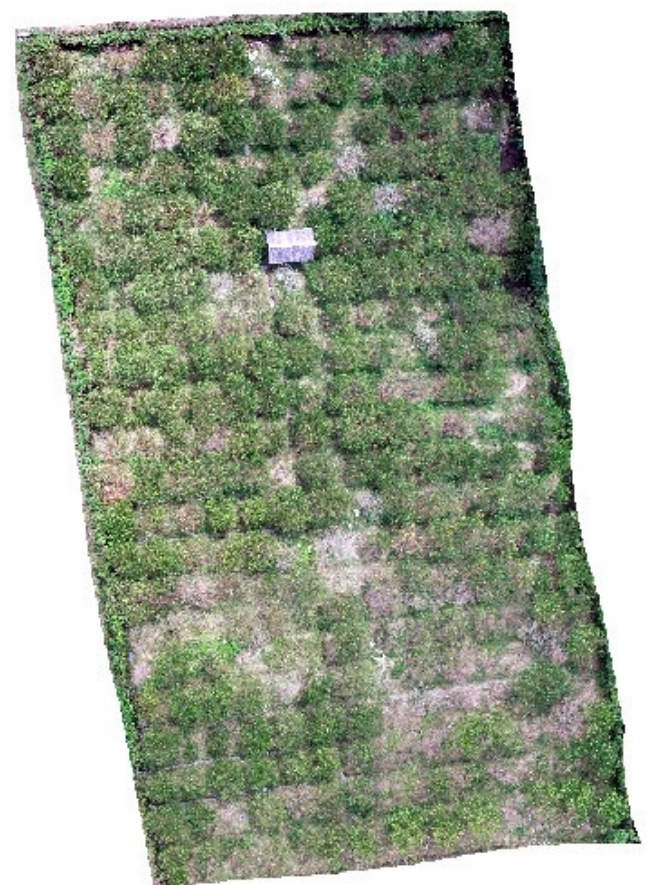

(a)
Hasil berbeda pada percobaan tanaman dewasa (gambar 5). Tanaman jeruk dewasa mempunyai kanopi yang sudah lebar sehingga bersinggungan antar tanaman. Hal ini berdampak pada objek yang diintrepretasikan akan lebih mudah. Intrepretasi citra menghasilkan tiga (3) kelas beserta prosentase luasnya yaitu sehat, sakit dan mati (gambar 6). Kemungkinan bias pada tanaman jeruk dewasa relatif kecil karena objek yang diintrepretasikan lebih sedikit.

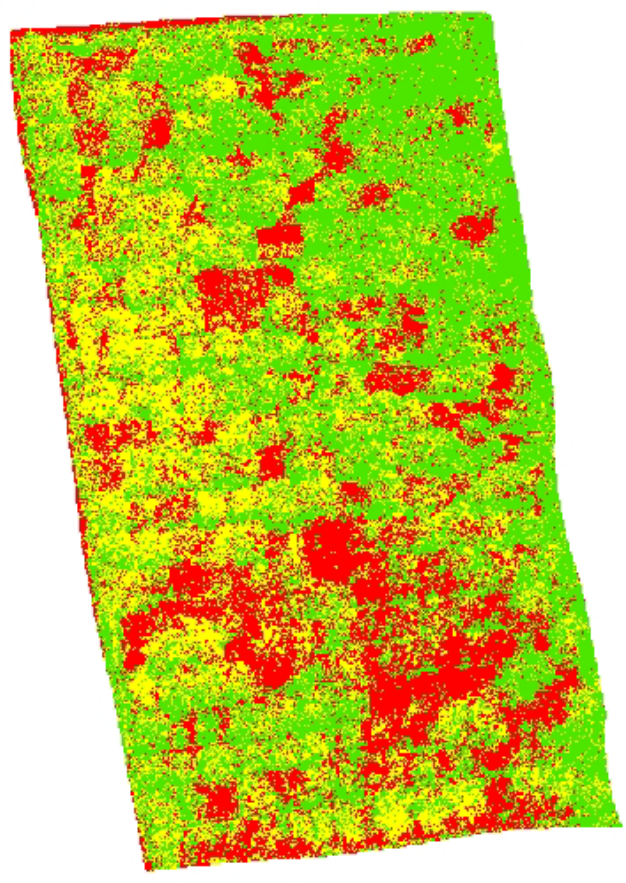

(b)

Gambar 5. Citra hasil drone (a) dan peta klasifikasi (b) tanaman jeruk dewasa

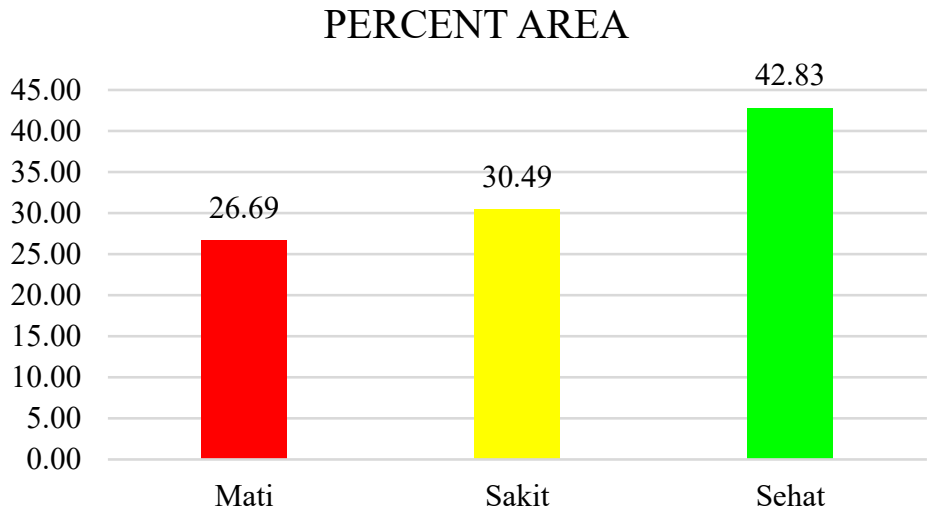

Gambar 6. Prosentase luas area klasifikasi citra drone pada tanaman jeruk dewasa 
Intrepretasi tanaman sehat dan sakit berdasarkan pada reflektan cahaya, jika hijau maka sehat dan kuning maka sakit. Hal ini perlu divalidasi lagi dengan analisa kandungan unsur hara dan penyakit. Daun berwarna kuning bisa disebabkan kekurangan unsur hara, serangan penyakit atau kekurangan air. Sedangkan interpretasi tanaman mati sudah sangat jelas dikarenakan bagian pohon yang tersisa adalah batang, cabang dan ranting.

\section{KESIMPULAN}

Berdasarkan hasil penelitian ini dapat disimpulkan sebagai berikut :

1. Drone dengan kamera RGB dapat digunakan untuk pemetaan kesehatan tanaman. Foto yang dihasilkan drone mempunyai resolusi tinggi sehingga individual tanaman terlihat jelas,

2. Klasifikasi kesehatan tanaman berdasarkan intrepretasi objek. Pada tanaman dewasa kemungkinan bias lebih sedikit dibandingkan tanaman muda disebabkan kanopi yang sudah bersinggungan.

3. Hasil klasifikasi berdasarkan image processing perlu divalidasi dengan analisa laboratorium agar hasil lebih akurat.

4. Perlu dilakukan penelitian lebih menggunakan kamera multispektral

\section{UACAPAN TERIMA KASIH}

Terima kasih terhadap Budianto selaku teknisi operasional drone.

\section{DAFTAR PUSTAKA}

CDCGC, 2004. Citrus and date crop germplasm Committee. USA. Citrus and Date Germplasm: Crop Vulnerability, Germplasm Activities, Germplasm Needs. Citrus and Date Crop Germplasm Committee, USA, pp. 1-30.

Statistik Produksi Hortikultura Tahun 2014. 2015. Direktorat Jenderal Hortikultura, Kementerian Pertanian.

Supriyanto A. 2010. Pengendalian Penyakit CVPD di Kabupaten Sambas - Kalimantan Barat. http://balitjestro.litbang.pertanian.go .id/. Tanggal akses 30 Juni 2021.

Rokhmana, C, A. 2015. The potential of UAV-based remote sensing for supporting precision agriculture in Indonesia. Procedia Environmental Science 24 hal 245-253.

Zabihi, H., Vogeler, I., Amin, Z.M., Gourabi, B.R., 2016. Mapping the sensitivity of citrus crops to freeze stress using a geographical information system in Ramsar, Iran. Weather and Climate Extremes 14, 17-23

Zabihi, H., Alizadeh, M., Vogeler, I., Ahmad, A., Said, M.N., Gourabi, B.R., 2017. Land allocation based on spatial analysis using artificial neural networks and GIS in Ramsar, Iran. Modeling Earth Systems and Environment 3 (4), 1515-1527. 